\title{
Pseudotumoral Fibrous Dysplasia Of The Maxilla.
}

\author{
AT KHARAT, A SINGH, VM KULKARNI, S OMAR
}

\section{Abstract}

Fibrous dysplasia is a skeletal disorder of unknown etiology usually affecting the young. Women are commonly affected more than men. Craniofacial fibrous dysplasia can have a varied presentation. It can affect the calvarium or the facial skeleton. These lesions typically expand the bone with intact well-preserved cortical rim. Here we present a case of pseudotumoral fibrous dysplasia with isolated involvement of the right maxilla.

Ind J Radiol Imag 2005 15:2:209-210

Keywords: Pseudotumoral, craniofacial, fibrous dysplasia, computed tomography.

Introduction:

Pseudotumoral fibrous dysplasia (1) involving the craniofacial bone is a rare developmental disorder that presents with varied radiological appearance and clinical presentations. Most of them are asymptomatic and present as rapidly growing lesion that causes typical facial asymmetry.

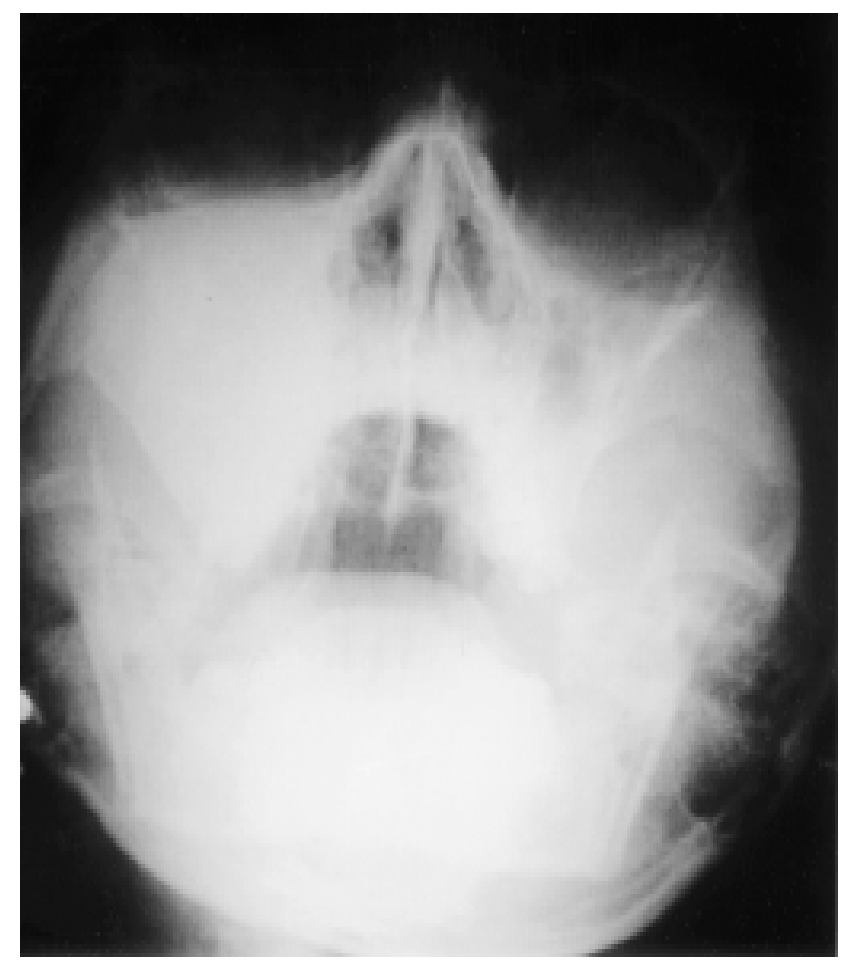

Figure 1: Radiograph of the paranasal sinuses - Water's view.

Expansion of the right maxillary sinus with ground glass appearance.

\section{Case History:}

An 18 years old girl presented with complaints of diplopia and facial asymmetry with rapidly growing painless, hard mass in the right cheek since last three months. No history of major systemic illness in the past. No history of trauma.

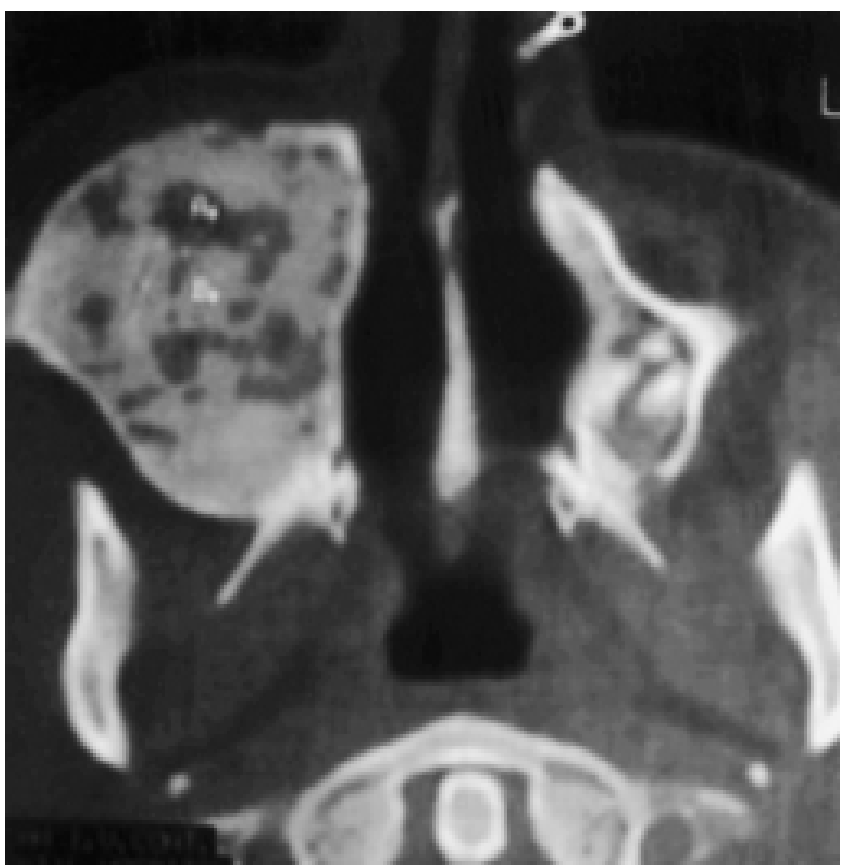

Figure 2: Axial CT scan image at the level of the maxillary sinus.

CT reveals sharply defined intact sinus walls with expansion of the right maxillary sinus and ground glass appearance with CT value of 150 to $400 \mathrm{HU}$.

From the Department of Radio diagnosis. Dr Padm D.Y. Patil Medical College. (Deemed University) Pimpri 18.

Request for Reprints: Dr Amit T Kharat, Flat No 2 Building No 34, Ranakpur Darshan Society, New Alandi Road, Vishrantwadi, Yerawada, Pune - 411006. 


\section{Findings:}

Radiograph of the paranasal sinus (Figure 1) revealed an opaque right maxillary sinus with sharp, well defined margins. There was significant expansion of the maxilla with ground glass appearance. No evidence of bone erosion or destruction. Rest of the sinuses were normal.

CT scan of the paranasal sinuses revealed a large, dense and expanded right maxillary sinus with ground glass appearance with CT value of 150 to $400 \mathrm{HU}$. (Figure 2)The surrounding cortical rim was preserved with no erosion or destruction. Within the expanded bone, cystic spaces with soft tissue density were noted. Inferiorly the lesion was extending into the alveolar process of the maxilla. Superiorly it was seen to deform the floor of the bony orbit. (Figure 3) No other lesions were noted. The diagnosis of pseudotumoral fibrous dysplasia was considered.

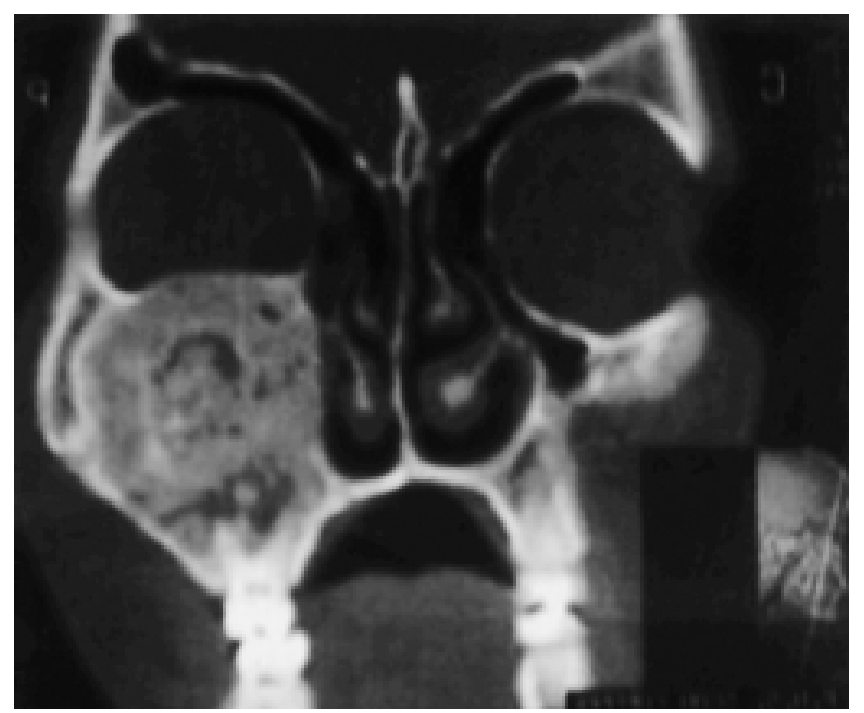

Figure 3: Coronal CT scan image at the level of the maxillary sinus.

There is superior displacement of the inferior orbital wall by the expanded sinus.

\section{Discussion:}

Fibrous dysplasia is an idiopathic lesion of the medullary bone. Majority of the cases are below 30 years of age (2). Pathologically lesions are characterized by replacement and distortion of the medullary bone by fibroosseous tissue of woven bone.

Pseudotumoral fibrous dysplasia of the maxilla is a rapidly developing form involving the maxilla (3). These lesions are notorious since they grow rapidly and there may be difficulty in interpretation in histological reports. These resemble tumor hence the name pseudotumoral fibrous dysplasia is used to describe rapidly growing and expanding lesions giving rise to facial deformity and asymmetry. The true nature of the lesion can be demonstrated on CT (4). Fibrous dysplasia can be monostotic or polyostotic. About 20 to $25 \%$ of monostotic dysplasia affects the head and neck; maxilla and the mandible are the most common sites (5).and 40 to $60 \%$ of polyostotic fibrous dysplasia affects the skull and facial bones (2), (5).

Bones affected with fibrous dysplasia can rarely undergo malignant degeneration (6). The appearance of new lesions usually terminates after skeletal maturity is attained.

Radiologic appearance varies according to the degree of fibrous tissue present. Bone texture varies from nonhomogenous mixture of bone and fibrous tissue to a ground glass appearance.

\section{Differential Diagnosis:}

Ossifying fibroma is a dense, well circumscribed lesion that ossifies from the periphery. This lesion unlike fibrous dysplasia contains lamellar rather than woven pattern of bone with normal number of osteoblasts and osteoclasts. Comparatively it is more aggressive with high recurrence rate, with a propensity of inward growth rather than create outer bone surface abnormalities.

\section{References:}

1. Gibson $\mathrm{M} \mathrm{J}$, Middlemiss $\mathrm{J} \mathrm{H}$ : Fibrous dysplasia of bone. Br J Radiol 44 (517):1-13,1971.

2. Barnes L. Verbin RS, Gnepp DR. Diseases of the nose, paranasal sinuses and nasopharynx. In: Barnes L, ed. Surgical pathology of the head and neck. Vol.1.New York, NY: Marcel Dekker Inc, 1985; 883-1044.

3. Vanel $D$, Couanet $D$, Micheau $C$ et al: Pseudotumoral fibrous dysplasia of the maxilla: Radiological studies and computed tomography contribution. Skeletal Radiol 5:99-103,1980.

4. Greenfield G B: Radiology of bone diseases. Ed fourth, J B Lippincott, Philadelphia, 3:129, 1986.

5. Dehner LP, Fibro-osseous lesions of the bone. In: Acerman LU, Spjut HJ, Abell MR,eds. Bones and joints. International Academy of Pathology, Monograph No.17.Baltimore, Md: Williams and Wilkins, 1976; 209235.

6. Riddell $\mathrm{D} M$ : Malignant change in fibrous dysplasia. $\mathrm{J}$ Bone Joint Surg [Br] 46:251-255,1964. 